\title{
FBXW7 missense mutation: a novel negative prognostic factor in metastatic colorectal adenocarcinoma
}

\author{
Krittiya Korphaisarn ${ }^{1,2}$, Van Karlyle Morris ${ }^{1}$, Michael J. Overman ${ }^{1}$, David R. \\ Fogelman ${ }^{1}$, Bryan K. Kee ${ }^{1}$, Kanwal Pratap Singh Raghav ${ }^{1}$, Shanequa Manuel ${ }^{1}$, \\ Imad Shureiqi ${ }^{1}$, Robert A. Wolff ${ }^{1}$, Cathy Eng ${ }^{1}$, David Menter ${ }^{1}$, Stanley R. Hamilton ${ }^{3}$, \\ Scott Kopetz ${ }^{1}$ and Arvind Dasari ${ }^{1}$ \\ ${ }^{1}$ Department of Gastrointestinal Medical Oncology, The University of Texas MD Anderson Cancer Center, Houston, TX, USA \\ ${ }^{2}$ Division of Medical Oncology, Department of Medicine, Faculty of Medicine, Siriraj Hospital, Bangkok, Thailand \\ ${ }^{3}$ Department of Pathology, The University of Texas MD Anderson Cancer Center, Houston, TX, USA \\ Correspondence to: Arvind Dasari, email: adasari@mdanderson.org \\ Keywords: colorectal cancer, FBXW7, mutation, missense, prognosis \\ Received: January 25, $2017 \quad$ Accepted: March 02, $2017 \quad$ Published: April 05, 2017 \\ Copyright: Korphaisarn etal. This is an open-access article distributed underthe terms of the Creative Commons Attribution License (CC-BY), \\ which permits unrestricted use, distribution, and reproduction in any medium, provided the original author and source are credited.
}

\section{ABSTRACT}

Background: $F B X W 7$ functions as a ubiquitin ligase tagging multiple dominant oncogenic proteins and commonly mutates in colorectal cancer. Data suggest missense mutations lead to greater loss of FBXW7 function than other gene aberrations do. However, the clinicopathologic factors and outcomes associated with FBXW7 missense mutations in metastatic colorectal cancer (mCRC) have not been described.

Methods: Data were obtained from mCRC patients whose tumors were evaluated by next-generation sequencing for hotspot mutations at The University of Texas MD Anderson Cancer Center. Alterations in FBXW7 were identified, and their associations with clinicopathologic features and overall survival (OS) were evaluated.

Results: Of 855 mCRC patients, 571 had data on FBXW7 status; 43 (7.5\%) had FBXW7 mutations, including 37 with missense mutations. R465C mutations in exon 9 were the most common missense mutations (18.6\%). PIK3CA mutations were associated with $F B X W 7$ missense mutations $(\mathrm{p}=0.012)$. On univariate analysis, patients with $F B X W 7$ missense mutations had significantly worse OS (median 28.7 mo) than those with wild-type $F B X W 7$ (median 46.6 mo; $p=0.003$ ). On multivariate analysis including other known prognostic factors such as BRAF mutations, FBXW7 missense mutations were the strongest negative prognostic factor for OS (hazard ratio $2.0 ; \mathrm{p}=0.003$ ).

Conclusions: In the largest clinical dataset of MCRC to date, FBXW7 missense mutations showed a strong negative prognostic association.

\section{INTRODUCTION}

Colorectal cancer (CRC) is the third most common cancer worldwide and the second most common cause of cancer-related mortality. It has been well established that colorectal tumorigenesis is a multistep process with an accumulation of multiple, successive genetic alterations, including chromosomal abnormalities, gene mutations, and/or epigenetic changes transforming normal colonic epithelium to colorectal carcinoma [1]. APC, TP53, RAS, $R A F$, and $P I K 3 C A$ gene mutations are the most commonly noted aberrations in metastatic CRC ( $\mathrm{mCRC})$. While the prognostic and predictive implications of a few such aberrations, including those of $R A F, R A S$, and deficient mismatch repair (MMR), are well established in CRC and now routinely assessed as part of clinical care [2-4], the clinical implications of other genetic aberrations in CRC are unclear in spite of extensive work over the past few decades. Intense research efforts are ongoing to identify reliable, novel biomarkers to help clinicians make personalized treatment decisions in CRC.

A potential avenue to this end involves ubiquitinmediated proteolysis, which regulates the degradation of 
many proteins involved in the control of cell growth and differentiation. F-box proteins, the substrate-recognition subunit of SKP1-Cullin1-F-box protein ubiquitin E3 ligase complexes, have been well characterized and shown to play important roles in degradation of proteins regulating cell cycle progression. So far, more than 70 putative F-box proteins have been identified in the human genome; however, the function and the substrates of most F-box proteins remain elusive [5].

$F B X W 7$ is a tumor suppressor gene on human chromosome $4 \mathrm{q}$ that encodes the substrate recognition components of SKP1-Cullin1-F-box protein ubiquitin E3 ligase complexes [6]. These specific E3 ligase complexes negatively regulate the intracellular abundance of an expanding list of key oncogenic proteins such as cyclin E [7], c-JUN [8, 9], c-MYC [10, 11], MCL1 (myeloid cell leukemia 1) [12, 13], NOTCH [14-17], AURKA (aurora kinase A) [18, 19], KLF5 (Krüppel-like factor 5) [20], mTOR [21], and TGIF1 [22]. Therefore, the loss of $F B X W 7$ function results in accumulation of its substrates, which leads to oncogenesis and progression of multiple cancers including CRC [23, 24]. A study of over 500 primary tumors of diverse tissue origins suggested that $F B X W 7$ mutations occurred in approximately $6 \%$ of all evaluated tumors. Of these, the most commonly affected tumors were cholangiocarcinoma (35\%), (T-cell acute lymphocytic leukemia, 31\%), endometrial cancer (9\%), and gastric cancer (6\%) [24]. $F B X W 7$ has also consistently been identified as one of the most commonly mutated genes in CRC [25], observed in $6 \%$ to $10 \%$ of all cases [24-27].

$F B X W 7$ is structurally composed of several conserved protein-protein interaction domains, including the 40-amino acid F-box, which recruits the SKP1Cullin1-F-box complex; eight WD40 repeats that bind to substrates; and the D domain located just before the F-box, which facilitates dimerization of $F B X W 7$. WD40 repeats 3 and 4 contain three highly conserved arginine residues that play a key role in binding to phosphothreonine residues on substrates, while residues within the other WD40 repeats contribute incrementally [28-31]. The $F B X W 7$ mutational range is rather atypical; over $70 \%$ are missense point mutations affecting amino acids within substrate-binding sites, and two of the key arginine residues described above ( $\mathrm{Arg}^{465}$ and $\mathrm{Arg}^{479}$ ) are mutational hotspots [5]. The rest are mostly nonsense mutations leading to premature termination of translation of $F B X W 7$, while the loss of an entire allele is very rarely noted [24]. Tumor-derived $F B X W 7$ alleles show a very strong predisposition for missense mutations over nonsense mutations. In fact, some tumor types such as T-cell acute lymphoblastic leukemia have only $F B X W 7$ missense mutations. This marked skew toward full-length $F B X W 7$ mutations with impaired substrate binding, instead of prematurely terminating mutants (due to nonsense mutations), is thought to be due to the former group's ability to act as more potent dominant negatives negating the impact of the wild-type protein in $F B X W 7$ dimers [5].

However, to date, the prognostic significance of $F B X W 7$ missense mutations in CRC remains to be elucidated. In the current study, we extensively evaluated the clinicopathologic and molecular characteristics of $F B X W 7$ missense mutations in $\mathrm{mCRC}$ and the associated survival outcomes.

\section{RESULTS}

A total of $855 \mathrm{mCRC}$ patients were included in the Assessment of Targeted Therapies Against Colorectal Cancer program at The University of Texas MD Anderson Cancer Center between February 13, 2009, and November 18,2015 . Of these, we identified 571 patients for the current study with data available on $F B X W 7$ status. The median age of the cohort was 55 years (range 20-82 years), and the ratio of males to females was 1.27 . The majority of primary tumors were left-sided colon tumors (243 patients, $42.6 \%$ ), followed by right-sided colon tumors (195 patients, 34.2\%), and the rest were rectal tumors (128 patients, $22.4 \%$ ). Patient and tumor characteristics are shown in (Table 1).

\section{Frequency of $K R A S, N R A S, B R A F, P I K 3 C A$, and $F B X W 7$ mutations and MSI-H}

DNA was extracted from 363 primary CRC tissues and 208 metastatic tissues. One hundred and ninety four cases were tested with the 46-gene panel while 377 cases were tested with the 50-gene panel. KRAS, NRAS, BRAF, and $P I K 3 C A$ mutations were present in $50.1 \%, 4.6 \%, 8.2 \%$, and $16.5 \%$, respectively, of the 571 patients in our cohort. $F B X W 7$ mutations were identified in 43 patients $(7.5 \%)$ (Table1). Of these, 37 patients had missense mutations, while four had nonsense mutations, one had insertion, and one had deletion. R465C in exon 9 affecting $\mathrm{Arg}^{465}$ was the most common $F B X W 7$ missense mutation (18.6\%). R465H (affecting $\mathrm{Arg}^{465}$ ) and R505C (affecting $\mathrm{Arg}^{505}$ ) were the second most common $F B X W 7$ missense mutations $(16.3 \%$ each). No difference in mutation frequency in $F B X W 7$ was noted either between primary $\mathrm{CRC}$ and metastatic tissues (8.8\% vs 5.3\%, respectively; $\mathrm{P}=0.12$ ) (Supplementary Table 1) or between the two gene panels $(7.2 \%$ vs $7.7 \%$, respectively; $\mathrm{p}=0.39$ ) (Supplementary Table 2). The frequencies and types of $F B X W 7$ mutations are shown in (Figure 1 and Supplementary Table 3). MSI-H was found in $3.3 \%$ of patients tested (19/414).

\section{Associations between $F B X W 7$ mutations and clinicopathologic factors}

The clinicopathologic variables compared with $F B X W 7$ status included age, sex, race/ethnicity, site of the primary tumor, histologic grade, and $K R A S, N R A S, B R A F$, $P I K 3 C A$, and microsatellite instability status. Among 
Table 1: Clinicopathological characteristics of study population, $\mathbf{n}(\%)$

\begin{tabular}{|c|c|c|}
\hline Variable & Value & $\%$ \\
\hline No. of patients & 571 & 100 \\
\hline Median age (yr, range) & $55,20-82$ & \\
\hline \multicolumn{3}{|l|}{ Age } \\
\hline$<50$ years & 197 & 34.5 \\
\hline$\geq 50$ years & 374 & 65.5 \\
\hline \multicolumn{3}{|l|}{ Sex } \\
\hline Female & 251 & 44 \\
\hline Male & 320 & 56 \\
\hline \multicolumn{3}{|l|}{ Race/ethnicity } \\
\hline Asian & 31 & 5.4 \\
\hline Black & 50 & 8.8 \\
\hline Hispanic & 54 & 9.5 \\
\hline White & 432 & 75.7 \\
\hline No data & 4 & 0.7 \\
\hline \multicolumn{3}{|l|}{ Primary tumor site } \\
\hline Right sided & 195 & 34.2 \\
\hline Left sided & 243 & 42.6 \\
\hline Rectum & 128 & 22.4 \\
\hline No data & 5 & 0.9 \\
\hline \multicolumn{3}{|l|}{ Metastases type } \\
\hline Synchronous & 368 & 64.4 \\
\hline Metachronous & 203 & 35.6 \\
\hline \multicolumn{3}{|l|}{ Metastatic site } \\
\hline Liver only & 51 & 8.9 \\
\hline Not Limited to Liver & 520 & 91.1 \\
\hline \multicolumn{3}{|l|}{ Differentiated } \\
\hline Well & 1 & 0.2 \\
\hline Mod & 423 & 74.1 \\
\hline Poorly & 141 & 24.7 \\
\hline No data & 6 & 1 \\
\hline \multicolumn{3}{|l|}{$K R A S$} \\
\hline wt & 284 & 49.7 \\
\hline $\mathrm{mt}$ & 286 & 50.1 \\
\hline variant & 1 & 0.2 \\
\hline \multicolumn{3}{|l|}{$N R A S$} \\
\hline wt & 545 & 95.4 \\
\hline $\mathrm{mt}$ & 26 & 4.6 \\
\hline
\end{tabular}




\begin{tabular}{lcc}
\hline Variable & Value & \% \\
\hline $\boldsymbol{B} \boldsymbol{R} \boldsymbol{A} \boldsymbol{F}$ & & 91.8 \\
$\mathrm{wt}$ & 524 & 8.2 \\
$\mathrm{mt}$ & 47 & \\
$\boldsymbol{P I} \boldsymbol{K} \boldsymbol{C} \boldsymbol{A}$ & & 83.5 \\
wt & 477 & 15.8 \\
mt & 90 & 0.7 \\
Variant & 4 & \\
MMR status & & 69.2 \\
Proficient & 395 & 3.3 \\
Deficient & 19 & 27.5 \\
No data & 157 & \\
$\boldsymbol{F} \boldsymbol{B} \boldsymbol{W} \boldsymbol{7}$ & & 92.3 \\
wt & 527 & 7.5 \\
mt & 43 & 0.2 \\
Variant & 1 & \\
\hline
\end{tabular}

wt: wild type, mt: mutation

these factors, only PIK3CA mutations were significantly associated with $F B X W 7$ mutations $(\mathrm{p}=0.012)$. A subset analysis limited to $F B X W 7$ missense mutations showed a similar association between the missense mutations and PIK3CA mutations $(\mathrm{p}=0.022)$ (Table 2). However, after excluding PIK3CA variant mutations $(\mathrm{n}=4)$, there was only a trend towards co-occurrence of PIK3CA and $F B X W 7$ mutations $(\mathrm{P}=0.10)$.

\section{Survival analysis}

The median follow-up time was 30.4 months. At the time of data cut-off (March 1, 2016), there were 266 patients alive and 305 patients who had died.

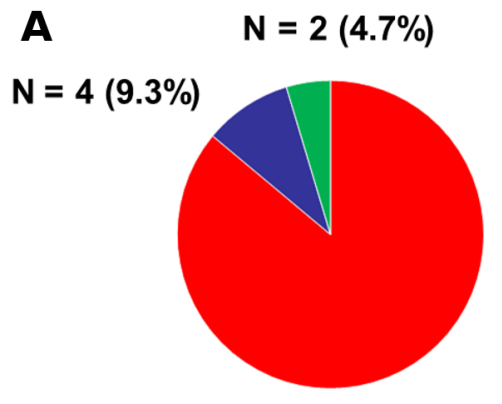

Univariate analysis of OS was performed using previously established prognostic factors: the aforementioned clinicopathologic variables as well as FBXW7 mutations. Factors that were associated with statistically significantly worse OS in this analysis included an age of $<50$ years $(\mathrm{p}=0.016)$, right-sided tumor origin $(\mathrm{p}<0.001)$, poor differentiation $(\mathrm{p}<0.001)$, $K R A S$ mutations $(\mathrm{p}<0.001), B R A F$ mutations $(\mathrm{p}=0.004)$, and PIK3CA mutations ( $\mathrm{p}=0.007)$. Patients with $F B X W 7$ mutations had significantly worse OS (median OS 31.3 mo, $95 \%$ confidence interval $[\mathrm{CI}] 18.7-43.9 \mathrm{mo}$ ) than patients with wild-type $F B X W 7$ (median OS $46.6 \mathrm{mo}$, 95\% CI 43.0-50.1 mo; $\mathrm{p}=0.002$ (Table 3, Figure 2A). Patients with $F B X W 7$ missense mutations had significantly

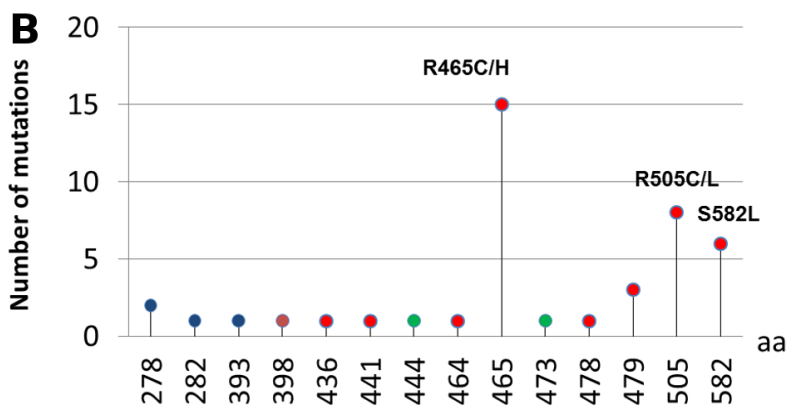

Figure 1: Frequency and spectrum of $\boldsymbol{F B} \boldsymbol{X} \boldsymbol{W} 7$ mutations. (A) $F B X W 7$ mutations were identified in 43 patients. Of these, 37 patients had missense mutations, while four had nonsense mutations, and two had frameshift mutations. (B) $\mathrm{R} 465 \mathrm{C} / \mathrm{H}$ were the most common $F B X W 7$ missense mutation (n=15). R505C/L were the second most common $F B X W 7$ missense mutations (n=8) followed by S582L missense mutations ( $\mathrm{n}=6$ ). 
Table 2: $F B X W 7$ status and associated clinicopathological factors

\begin{tabular}{|c|c|c|c|c|c|c|c|c|}
\hline \multirow[t]{3}{*}{ Variable } & \multicolumn{8}{|c|}{$F B X W 7$ status } \\
\hline & \multicolumn{2}{|c|}{ wt } & \multicolumn{3}{|c|}{ All $F B X W 7$ mutations } & \multicolumn{3}{|c|}{$F B X W 7$ missense mutations } \\
\hline & $\mathbf{N}$ & $\%$ & $\mathbf{N}$ & $\%$ & P value & $\mathbf{N}$ & $\%$ & P value \\
\hline \multicolumn{9}{|l|}{ Age $(N=570)$} \\
\hline$<50$ years & 183 & 34.7 & 14 & 32.6 & 0.77 & 13 & 35.1 & 0.96 \\
\hline$\geq 50$ years & 344 & 65.3 & 29 & 67.4 & & 24 & 64.9 & \\
\hline \multicolumn{9}{|l|}{$\operatorname{Sex}(N=570)$} \\
\hline Female & 233 & 44.2 & 18 & 41.9 & 0.77 & 14 & 37.8 & 0.45 \\
\hline Male & 294 & 55.8 & 25 & 58.1 & & 23 & 62.2 & \\
\hline \multicolumn{9}{|l|}{$\begin{array}{l}\text { Race/ethnicity } \\
(\mathrm{N}=566)\end{array}$} \\
\hline Asian & 29 & 5.5 & 2 & 4.7 & 0.99 & 1 & 2.7 & 0.89 \\
\hline Black & 46 & 8.8 & 4 & 9.3 & & 3 & 8.1 & \\
\hline Hispanic & 50 & 9.6 & 4 & 9.3 & & 4 & 10.8 & \\
\hline White & 398 & 76.1 & 33 & 76.7 & & 29 & 78.4 & \\
\hline \multicolumn{9}{|l|}{$\begin{array}{l}\text { Primary tumor site } \\
(\mathrm{N}=565)\end{array}$} \\
\hline Rt.sided & 182 & 34.9 & 12 & 27.9 & 0.42 & 8 & 21.6 & 0.17 \\
\hline Lt.sided & 225 & 43.1 & 18 & 41.9 & & 17 & 45.9 & \\
\hline Rectum & 115 & 22 & 13 & 30.2 & & 12 & 32.4 & \\
\hline \multicolumn{9}{|l|}{ Metastases type } \\
\hline Synchronous & 341 & 64.7 & 26 & 60.5 & 0.58 & 21 & 56.8 & 0.33 \\
\hline Metachronous & 186 & 35.3 & 17 & 39.5 & & 16 & 43.2 & \\
\hline \multicolumn{9}{|l|}{ Metastatic site } \\
\hline Liver only & 46 & 8.7 & 5 & 11.6 & 0.52 & 4 & 10.8 & 0.67 \\
\hline Not Limited to Liver & 481 & 91.3 & 38 & 88.4 & & 33 & 89.2 & \\
\hline \multicolumn{9}{|l|}{$\begin{array}{l}\text { Differentiated } \\
(\mathrm{N}=564)\end{array}$} \\
\hline Well to moderately & 392 & 45.2 & 32 & 74.4 & 0.91 & 27 & 73 & 0.76 \\
\hline Poorly & 129 & 24.8 & 11 & 25.6 & & 10 & 27 & \\
\hline \multicolumn{9}{|l|}{$K R A S(\mathrm{~N}=569)$} \\
\hline wt & 265 & 50.4 & 19 & 44.2 & 0.44 & 15 & 40.5 & 0.25 \\
\hline $\mathrm{mt}$ & 261 & 49.6 & 24 & 55.8 & & 22 & 59.5 & \\
\hline \multicolumn{9}{|l|}{$N R A S(\mathrm{~N}=570)$} \\
\hline wt & 503 & 95.4 & 41 & 95.3 & 1 & 35 & 94.6 & 0.69 \\
\hline $\mathrm{mt}$ & 24 & 4.6 & 2 & 4.7 & & 2 & 5.4 & \\
\hline \multicolumn{9}{|l|}{$B R A F(\mathrm{~N}-570)$} \\
\hline wt & 485 & 92 & 38 & 88.4 & 0.39 & 33 & 89.2 & 0.53 \\
\hline $\mathrm{mt}$ & 42 & 8 & 5 & 11.6 & & 4 & 10.8 & \\
\hline
\end{tabular}




\begin{tabular}{|c|c|c|c|c|c|c|c|c|}
\hline \multirow[t]{3}{*}{ Variable } & \multicolumn{8}{|c|}{$F B X W 7$ status } \\
\hline & \multicolumn{2}{|c|}{ wt } & \multicolumn{3}{|c|}{ All $F B X W 7$ mutations } & \multicolumn{3}{|c|}{$F B X W 7$ missense mutations } \\
\hline & $\mathbf{N}$ & $\%$ & $\mathbf{N}$ & $\%$ & P value & $\mathbf{N}$ & $\%$ & P value \\
\hline \multicolumn{9}{|c|}{$P I K 3 C A(\mathrm{~N}=570)$} \\
\hline wt & 446 & 84.6 & 30 & 69.8 & 0.012 & 26 & 70.3 & 0.022 \\
\hline $\mathrm{mt}$ & 81 & 15.4 & 13 & 30.2 & & 12 & 29.7 & \\
\hline \multicolumn{9}{|c|}{ MMR status (N=414) } \\
\hline Proficient & 365 & 96.1 & 30 & 88.2 & 0.06 & 26 & 89.7 & 0.13 \\
\hline Deficient & 15 & 3.9 & 4 & 11.8 & & 3 & 10.3 & \\
\hline
\end{tabular}

wt: wild type, mt: mutation

worse OS (median OS 28.7 mo, 95\% CI 17.8-39.6 mo) than patients with other $F B X W 7$ mutations (median OS 43.0 mo, 95\% CI not reached (Table 3, Figure 2B).We also looked at $F B X W 7^{\text {arg }}$ and other missense mutations but found no significant associated prognostic effects (Supplementary Figure 1).

Multivariate Cox proportional hazards regression analysis of OS was performed using the factors mentioned above. In this analysis, FBXW7 missense mutations emerged as the strongest negative prognostic factor for OS (hazard ratio [HR] 2, 95\% CI 1.3-3.2; $\mathrm{p}=0.003)$. Other factors associated with worse OS were an age of $<50$ years (HR 1.4, 95\% CI 1.1-1.8; $\mathrm{p}=0.006$ ), right-sided tumor origin (HR 1.5, 95\% CI 1.0-2.1; $\mathrm{p}=0.031$ ), poor differentiation (HR 1.5, 95\% CI 1.2-2.0; $\mathrm{p}=0.001$ ), KRAS mutations (HR 1.5, 95\% CI 1.1-1.9; $\mathrm{p}=0.004$ ), and $B R A F$ mutations (HR 1.7, 95\% CI 1.1-2.7; $\mathrm{p}=0.015)($ Table 3, Figure 3).

\section{DISCUSSION}

In this large cohort of mCRC patients, those who harbored $F B X W 7$ mutations had significantly worse survival. We showed for the first time that $F B X W 7$ missense mutations portend a worse prognosis in this population than do other type of mutations

In $\mathrm{CRC}$, the frequency of $F B X W 7$ mutations has been shown to vary between $6 \%$ and $10 \%$ and is consistently one of the most frequently mutated genes [24-27]. In our study, the frequency of $F B X W 7$ mutations was $7.5 \%$, which is consistent with prior studies. In a study by Akhoondi et al. [24] using 1556 samples from a wide range of cancers, including $523 \mathrm{CRC}$ samples, the most frequently noted mutations were single-nucleotide changes, commonly missense mutations, of which nearly half ( $43 \%$ ) occurred at two mutation hotspots positioned at codons $\operatorname{Agr}^{465}(29 \%)$ and $\operatorname{Arg}^{479}(14 \%)$. Other mutation hotspots detected in that study were at $\operatorname{Ser}^{582}(4 \%)$, $\operatorname{Arg}^{278}$ (4\%), $\operatorname{Arg}^{224}$ (3\%), and $\operatorname{Arg}^{393}$ (3\%). Jardim et al. [32] reported similar results in which the most common mutations were in two hot spots at codons $\mathrm{Arg}^{465}$ and $\mathrm{Arg}^{479}$.
In our study, most of the detected $F B X W 7$ mutations were missense $(37 / 43,86 \%)$. FBXW7 mutations were most commonly found in codon $\operatorname{Arg}^{465}$ (15 cases, 34.9\%) and were observed in codon $\mathrm{Arg}^{479}$ in only three cases (7\%). Interestingly, our study had a slightly higher frequency of FBXW7 mutations in codon $\mathrm{Arg}^{505}$ (eight cases, 18.6\%) than previously described [24, 32]. S582L was noted in six cases $(14 \%)$ and was the third most common $F B X W 7$ mutation in our study. Chang et al. [33] reported a similar frequency of $F B X W 7$ mutations $(7.5 \%, 114 / 1519)$ in CRC patients but noted that $\mathrm{Ser}^{582}$ (S582L) was the most frequent type (19.3\%), ahead of $\mathrm{Arg}^{465}(\mathrm{R} 465 \mathrm{H}, 16.6 \%)$, $\operatorname{Arg}^{505}$ (R505C, 14.9\%), and $\operatorname{Arg}^{479}$ (R479Q, 14.9\%). These variations are slight and within the realm of inter-study statistical variations. Furthermore, data from the Cancer Genome Atlas Network [34] project confirm that missense mutations affecting the hotspot arginine residues are the most common types in CRC, validating our findings.

$F B X W 7$ missense mutations, especially those that are $F B X W 7^{\text {Arg }}$ mutations, have a much more profound impact on substrate binding activity than other $F B X W 7$ gene aberrations because these residues make up a critical substrate-binding interface, and thus disrupt substrate binding [29, 30]. Most of the remaining $F B X W 7$ mutations are nonsense codons that lead to premature termination of $F B X W 7$ translation that largely leads to production of non-functional alleles that may or may not dimerize. In contrast, full-length missense mutations result in alleles with dominant negative activity. Multiple mechanisms have been proposed for the more profound effects of missense mutations, including dominant negative effects on wild-type $F B X W 7$ in dimers by retaining partial activity and stably binding to substrates, preventing their accessibility to wild-type $F B X W 7$ monomers. Overall, these data suggest that missense mutations in a single allele of $F B X W 7$ impair the activity of $F B X W 7$ more profoundly than either allelic loss or stop codons. These data were confirmed in a CRC mouse model with $F B X W 7^{\mathrm{Arg} /+}$ that showed increased tumorigenesis compared with $F B X W 7^{+-}$ mice. In this model, downstream $F B X W 7$ substrates were elevated in $F B X W 7^{\mathrm{Arg} /+}$ but not in $F B X W 7^{+/-}$tumors [35]. 
Table 3: Survival analysis

\begin{tabular}{|c|c|c|c|c|c|c|c|}
\hline \multirow[t]{2}{*}{ Variables } & \multirow[t]{2}{*}{$\mathbf{N}$} & \multicolumn{3}{|c|}{ Univariate analysis } & \multicolumn{3}{|c|}{ Multivariate analysis } \\
\hline & & $\begin{array}{c}\text { Median survival } \\
\text { (mo) }\end{array}$ & $95 \% \mathrm{CI}$ & P value & HR & $95 \% \mathrm{CI}$ & P value \\
\hline \multicolumn{8}{|l|}{ Age } \\
\hline$<50$ years & 197 & 40.96 & $34.88-47.05$ & 0.016 & 1.42 & $1.10-1.83$ & 0.006 \\
\hline$\geq 50$ years & 373 & 47.57 & $43.58-51.56$ & & Ref & & \\
\hline \multicolumn{8}{|l|}{ Sex } \\
\hline Female & 251 & 45.47 & $41.19-49.75$ & 0.842 & & & \\
\hline Male & 320 & 45.70 & $39.61-51.78$ & & & & \\
\hline \multicolumn{8}{|l|}{ Site } \\
\hline Rt.sided & 195 & 38.20 & $30.33-46.07$ & $<0.001$ & 1.46 & $1.03-2.05$ & 0.031 \\
\hline It.sided & 243 & 50.27 & $44.92-55.62$ & & 0.98 & $0.71-1.34$ & 0.891 \\
\hline Rectum & 128 & 48.33 & $40.44-56.22$ & & Ref & & \\
\hline \multicolumn{8}{|l|}{ Differentiated } \\
\hline Well to moderately & 424 & 48.26 & $44.34-52.19$ & $<0.001$ & Ref & & \\
\hline Poorly & 141 & 36.49 & $28.61-44.38$ & & 1.52 & $1.18-1.96$ & 0.001 \\
\hline \multicolumn{8}{|l|}{$K R A S$} \\
\hline wt & 284 & 50.47 & $43.62-57.31$ & $<0.001$ & Ref & $1.13-1.91$ & 0.004 \\
\hline $\mathrm{mt}$ & 286 & 41.03 & $35.41-46.65$ & & 1.47 & & \\
\hline \multicolumn{8}{|l|}{$N R A S$} \\
\hline wt & 545 & 45.67 & $42.28-49.06$ & 0.163 & & & \\
\hline $\mathrm{mt}$ & 26 & 37.18 & $29.37-45.00$ & & & & \\
\hline \multicolumn{8}{|l|}{$B R A F$} \\
\hline wt & 524 & 46.55 & $42.72-50.39$ & 0.004 & Ref & & \\
\hline $\mathrm{mt}$ & 47 & 37.71 & $16.55-58.87$ & & 1.72 & $1.11-2.67$ & 0.015 \\
\hline \multicolumn{8}{|l|}{ PIK3CA } \\
\hline wt & 477 & 47.24 & $43.55-50.94$ & 0.007 & Ref & & \\
\hline $\mathrm{mt}$ & 94 & 40.73 & $31.54-49.93$ & & 1.12 & $0.83-1.52$ & 0.451 \\
\hline \multicolumn{8}{|l|}{ MMR status } \\
\hline Proficient & 395 & 45.67 & $40.82-50.51$ & 0.073 & Ref & & \\
\hline Deficient & 19 & 35.93 & $14.76-57.10$ & & 1.53 & $0.72-3.24$ & 0.270 \\
\hline Unknown & 157 & 45.70 & $39.95-51.45$ & & 1.13 & $0.88-1.45$ & 0.352 \\
\hline \multicolumn{8}{|l|}{$F B X W 7$} \\
\hline wt & 527 & 46.55 & $43.00-50.11$ & 0.003 & Ref & & \\
\hline Missense mt & 37 & 28.67 & $17.76-39.58$ & & 2.0 & $1.27-3.16$ & 0.003 \\
\hline Other mt & 6 & 42.97 & Not reached & & 0.98 & $0.24-4.08$ & 0.980 \\
\hline
\end{tabular}

wt: wild type, mt: mutation, Ref: reference 
In our study, multivariate analysis demonstrated that $F B X W 7$ missense mutations were independently associated with poor OS in $\mathrm{mCRC}$ and in fact were the strongest negative prognostic factor (HR 2.0) (Figure 3). In particular, $F B X W 7$ missense mutations had a stronger prognostic association with OS than all $F B X W 7 \mathrm{mt}$ or nonmissense mutations. This finding confirms our hypothesis that $F B X W 7$ mutation type has prognostic implications. Given the small numbers in the current study, these results will need to be confirmed in larger datasets.

In contrast to our study, several other CRC studies evaluating the prognostic effects of $F B X W 7$ mutations have shown varying and even conflicting results from ours. In a study of 1,519 patients with CRC at all stages, Chang et al. [33] showed that $F B X W 7$ mutations did not impact prognosis. In fact, in that study, subgroup analyses of $F B X W 7$ mutations showed that $\mathrm{R} 465 \mathrm{H}, \mathrm{R} 465 \mathrm{C}$, and R479Q were associated with better 5-year OS rates than other $F B X W 7$ mutation types were $(76.9 \%$ vs $56.0 \%$; $\mathrm{p}=0.012$ ). Similarly, in the VICTOR trial report, $F B X W 7$ mutations were not associated with disease-free survival in stage II/III CRC [36]. Finally, data from The Cancer Genome Atlas suggest that $F B X W 7$ mutations were not associated with overall survival. How do we explain these disparate findings? One obvious explanation would be the difference in patient populations. All these datasets
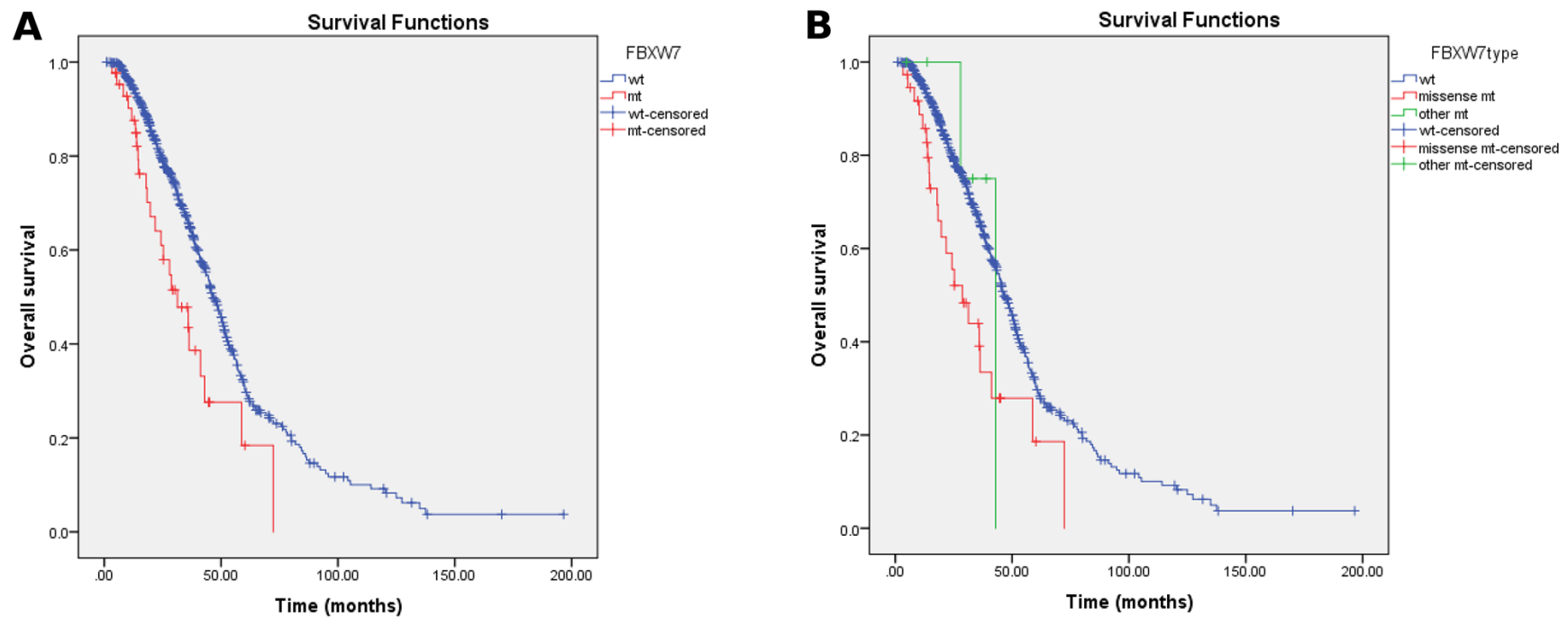

Figure 2: Kaplan-Meier survival curves according to $\boldsymbol{F B} \boldsymbol{X} \boldsymbol{W} 7$ status. (A) Patients with $F B X W 7$ mutations had significantly worse OS (median OS 31.3 mo, 95\% confidence interval [CI] 18.7-43.9 mo) than patients with wild-type $F B X W 7$ (median OS 46.6 mo, 95\% CI 43.0-50.1 mo; $\mathrm{p}=0.002$ ). (B) Patients with FBXW7 missense mutations had significantly worse OS (median OS $28.7 \mathrm{mo}, 95 \%$ CI 17.8-39.6 mo) than patients with other $F B X W 7$ mutations "(median OS $43.0 \mathrm{mo}, 95 \%$ CI not reached; $\mathrm{p}=0.003$ ).

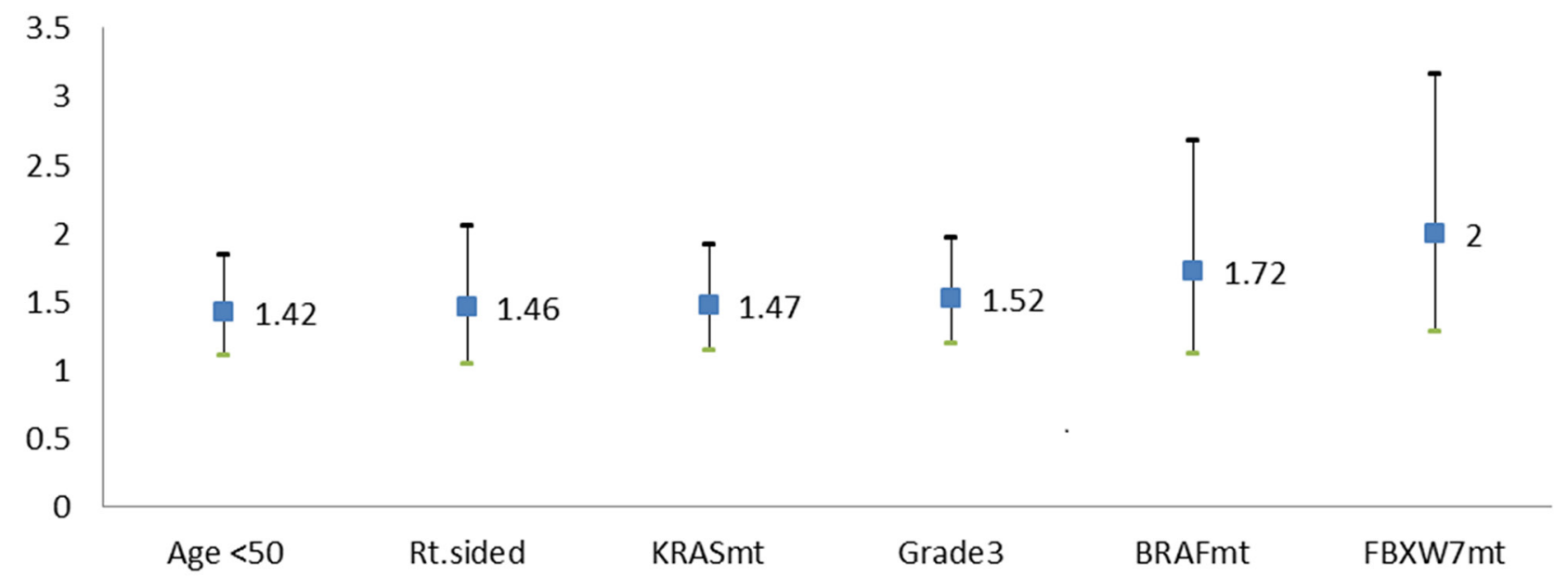

Figure 3: Negative prognostic factors for OS rate (HR with $95 \%$ CI). Factors associated with worse OS were an age of $<50$ years (HR 1.42), right-sided tumor origin (HR 1.46), KRAS mutations (HR 1.47), poor differentiation (HR 1.52), BRAF mutations (HR 1.72), and $F B X W 7$ mutations ( $\mathrm{HR}=2)$. 
included predominantly early-stage disease, while our study was limited to patients with metastatic disease. The differential prognostic effect of a biomarker across advancing stages of CRC is a well-established concept. For instance, $B R A F$ gene mutations are a known strong negative prognostic maker for stage IV CRC [2, 37] but not stage II-III CRC [38]. Similarly, MSI-H has positive prognostic effects in early-stage CRC but little if any in stage IV CRC [4]. Secondly, these studies looked at different end points, ranging from disease-free survival to OS. Finally, as demonstrated in multiple studies [29, $30,35]$ missense mutations have much more profound implications than other mutations do, which was not specifically addressed in the prior studies. Future studies should be designed to specifically evaluate the role of missense mutations, especially in the metastatic setting.

Our study demonstrated the co-occurrence of $F B X W 7$ mutations with PIK3CA mutations ( $\mathrm{p}=0.012)$. However, after excluding PIK3CA variants in codon I391M which could be potential germline polymorphisms [39] (4 cases), there was only a tendency towards co-occurrence of these two mutations $(\mathrm{P}=0.10)$. The TCGA dataset [34] from 212 sequenced $\mathrm{CRC}$ cases suggests that $F B X W 7$ mutations co-occur with $B R A F$ mutations $(\mathrm{p}=0.03)$ and also have a tendency towards cooccurrence with PIK3CA mutations $(\mathrm{p}=0.25)$. It should be noted that TCGA dataset did not include PIK3CA I391M variants in their analysis. Alternatively, this difference might also be related to the difference in study populations with our study including only advanced stage of tumor while TCGA dataset included all stages with only 29/212 (13.7\%) being stage IV. The correlation between $F B X W 7$ mutations with other gene mutations across different stages needs to be validated in future studies. Lupini et al. reported that $F B X W 7$ mutations were associated with resistance to anti-epidermal growth factor receptor antibodies (anti-EGFRab). The ability to predict response to anti-EGFRab in KRAS WT patients was significantly improved by adding $F B X W 7$ to a $N R A S-B R A F$ $P I K 3 C A$ mutation panel ( $\mathrm{P}=0.016$ and 0.045 respectively). In this study, the prevalence of $F B X W 7 \mathrm{mt}$ was $17.8 \%(5 / 28$ cases) and $2.7 \%$ (1/37 cases) in the non-responder and responder groups, respectively $(\mathrm{P}=0.08)$. [40]. However, this is a small dataset and requires further larger studies to confirm this effect.

An obvious direction of future work based on the current findings would be $F B X W 7$-directed therapy. Directly, targeting $F B X W 7$ mutations may be challenging given the disparate spectrum of changes noted and as yet unclear implications of the various aberrations. An easier and more direct approach might be targeting the downstream oncogenic substrates of $F B X W 7$. Since $F B X W 7$ has multiple substrates, it would be important to identify the most important ones in mCRC. Aydin et al. [41] reported that $F B X W 7$ mutational inactivation represents a mechanism for $\mathrm{NOTCH} 1$ activation in melanoma and that anti-NOTCH treatment strategies showed promise in reduction of tumor growth in a xenograft model, making the NOTCH pathway a compelling target for therapeutic intervention. Similar findings have been noted in T-cell acute lymphocytic leukemia as well [42]. Intriguingly, a study by Sancho et al. in $\mathrm{APC}^{\mathrm{min} / \mathrm{H}}$ mouse models lacking $F B X W 7$ activity in the intestine showed more aggressive adenomatous polyposis coli-mediated tumorigenesis and progression. These tumors were noted to have an abundance of Notch pathway substrates. These findings were confirmed in a small set of human CRC samples (five tumor and six control samples) that confirmed increased Notch activity, suggesting that a failure to antagonize Notch activity is an evolutionarily conserved mechanism of loss of function of $F B X W 7[43]$. Whether the Notch pathway is truly activated in CRC patients with $F B X W 7$ mutations and whether the pathway would serve as a predictive biomarker for Notch pathway inhibitors will need to be evaluated.

Our study had several limitations. Firstly, it has the inherent drawbacks of a retrospective study. Secondly, our analysis of $F B X W 7$ function was limited to only hotspot $F B X W 7$ gene mutations, and therefore it is likely we missed other mechanisms leading to the loss of function of this protein, including other gene aberrations (such as truncation or deletion) or post-translational modifications. However, to the best of our knowledge, this is the first study to report the clinical characteristics and outcomes associated with $F B X W 7$ missense mutations in $\mathrm{mCRC}$ and show the strong negative prognostic effects of such mutations.

In summary, this is the first and largest clinical dataset of $F B X W 7$ missense mutations which showed negative prognostic impact on survival in mCRC. Since $F B X W 7$ was found more frequently in CRC and since most $F B X W 7$ substrates are oncoproteins, further studies are required to identify downstream pathways underlying this worse prognosis and potential therapeutic targets.

\section{MATERIALS AND METHODS}

In this single-institution, retrospective study, medical records of patients with $\mathrm{mCRC}$ who were enrolled in the Assessment of Targeted Therapies Against Colorectal Cancer program at The University of Texas MD Anderson Cancer Center between February 13, 2009, and November 18,2015 , were reviewed, and only patients who had nextgeneration sequencing data available were included in the study. The study protocol was approved by the MD Anderson Cancer Center institutional review board. All patients provided written informed consent for sequencing of their tumors according to institutional guidelines. The primary objective of this study was to determine the prognostic effect of $F B X W 7$ missense mutations on overall survival (OS); the secondary objectives were to examine associations between $F B X W 7$ mutations and various clinicopathologic characteristics and to evaluate the prognostic effect of all $F B X W 7$ mutations, irrespective of type, on OS. 


\section{Clinical characteristics}

Demographic information including age, sex, race, primary tumor site, date of diagnosis with stage IV disease, date of last follow-up, and date of death were collected from the review of the medical records. Right-sided colon cancer was defined as cancer in the region from the cecum to the splenic flexure, while left-sided colon cancer was defined as cancer in the region from the descending colon through the sigmoid colon, and the rectum was considered a separate site. Staging was done per the American Joint Committee on Cancer/Union for International Cancer Control TMN staging system (version 7, 2010) [44]. OS was defined as the interval between the date of diagnosis of metastatic disease and the date of death from any cause; patients alive at the time of analysis were censored at their last known follow-up date.

\section{Molecular characterization}

DNA was extracted from paraffin-embedded formalin-fixed tumor tissue. Samples were evaluated by using a next-generation sequencing platform with 46- or 50-gene panels for the detection of frequently reported point mutations in human malignancies in a Clinical Laboratory Improvement Amendments-certified molecular diagnostics laboratory which determined the effective lower limit of detection (analytical sensitivity) for single nucleotide variations to be in the range of 5\% (one mutant allele in the background of nineteen wild type alleles) to $10 \%$ (one mutant allele in the background of nine wild type alleles). Details of codons and exons tested in KRAS, NRAS, BRAF, PIK3CA, and FBXW7 are shown in (Supplementary Table 4).

\section{Determination of MMR status by microsatellite instability testing}

MMR status was determined by immunohistochemical analysis of MMR protein expression or by polymerase chain reaction analysis of microsatellite instability. Deficient MMR was defined as the presence of high-level microsatellite instability on polymerase chain reaction and/or as the loss of MMR protein expression on immunohistochemical analysis. Proficient MMR was defined as the presence of microsatellite stability or low-level microsatellite instability on polymerase chain reaction and/or as the presence of normal MMR protein expression on immunohistochemical analysis.

\section{Immunohistochemical analysis of MMR expression}

Immunoperoxidase stains were performed on sections from formalin-fixed paraffin-embedded tissues with antibodies for the DNA mismatch repair enzymes MLH1, MSH2, MSH6, and PMS2. Staining for MMR proteins was performed using the following primary antibodies: mouse anti-human MLH1 (clone G168-728; Cell Marque Corporation, Rocklin, CA), 1:300 dilution; mouse antihuman MSH2 (clone FE11; Calbiochem/Oncogene Research Products, Cambridge, MA), 1:100 dilution; mouse antihuman MSH6 (clone 44; BD Biosciences, San Jose, CA), 1:300 dilution; and mouse anti-human PMS2 (clone A16-4; BD Biosciences), 1:125 dilution. Loss of MMR protein was defined as the absence of nuclear staining of tumor cells in the presence of positive nuclear staining in normal epithelial cells and lymphocytes. Interpretation of immunohistochemistry for mismatch repair status is shown in (Supplementary Table 1).

\section{Polymerase chain reaction analysis for microsatellite instability testing}

DNA extracted from microdissected paraffinembedded tumor sections and non-neoplastic tissues was analyzed by a polymerase chain reaction-based method followed by capillary electrophoretic detection. A panel of seven microsatellite markers (BAT25, BAT26, BAT40, D2S123, D5S346, D17S250, and TGFBR2) was evaluated to detect changes in the number of microsatellite repeats in tumor tissue compared with normal tissue. Tumors were classified as MSI-H ( $>40 \%$ of markers altered), MSI-L $(<40 \%$ of markers altered) and MSS (no marker altered).

\section{Statistical analysis}

Patient characteristics were summarized with descriptive statistics. The relationships between clinicopathologic variables and $F B X W 7$ status were assessed using Pearson's $\chi^{2}$ or Fisher exact test as appropriate. The associations of patient and molecular characteristics with OS were assessed by Kaplan-Meier estimation, log-rank test, and Cox proportional hazards regression models. Median follow-up time was calculated using the reverse Kaplan-Meier method. All tests were two-sided, and $\mathrm{p}<0.05$ was considered statistically significant. Calculations were carried out using SPSS version 23.0 software (IBM Corporation, Armonk, NY).

\section{Abbreviations}

CRC: colorectal cancer; mCRC: metastatic colorectal cancer; OS: overall survival; MMR: mismatch repair; MCL1: myeloid cell leukemia 1; AURKA: Aurora kinase A; KLF5: Krüppel-like factor 5; MSI: Microsattelite instability; antiEGFRab: anti-epidermal growth factor receptor antibodies

\section{Author contributions}

KK performed the research, data collection, acquired and analyzed the data, and drafted the manuscript. SM participated in data collection. VKM, MJO, DRF, BK, KPSR, IS, KE, DM, SRH, and SK participated in revised 
the manuscript for important intellectual content. AD designed the study, supervised the study, critically revised the manuscript, and approved the final version for publication. All authors read, reviewed, and approved the final manuscript.

\section{ACKNOWLEDGMENTS}

The University of Texas MD Anderson Cancer Center is supported in part by the National Institutes of Health through Cancer Center Support Grant P30CA016672.

\section{CONFLICTS OF INTEREST}

The authors declare that no conflicts of interest exist.

\section{FUNDING}

The University of Texas MD Anderson Cancer Center is supported by the NCI Core Center Grant 5P30CA016672-39

\section{REFERENCES}

1. Vogelstein B, Fearon ER, Hamilton SR, Kern SE, Preisinger AC, Leppert M, Nakamura Y, White R, Smits AM, Bos JL. Genetic alterations during colorectal-tumor development. N Engl J Med. 1988; 319: 525-532.

2. Therkildsen C, Bergmann TK, Henrichsen-Schnack T, Ladelund S, Nilbert M. The predictive value of kras, nras, braf, pik3ca and pten for anti-egfr treatment in metastatic colorectal cancer: a systematic review and meta-analysis. Acta Oncol. 2014; 53: 852-864.

3. Rowland A, Dias MM, Wiese MD, Kichenadasse G, McKinnon RA, Karapetis CS, Sorich MJ. Meta-analysis of braf mutation as a predictive biomarker of benefit from antiegfr monoclonal antibody therapy for ras wild-type metastatic colorectal cancer. Br J Cancer. 2015; 112: 1888-1894.

4. Popat S, Hubner R, Houlston RS. Systematic review of microsatellite instability and colorectal cancer prognosis. J Clin Oncol. 2005; 23: 609-618.

5. Welcker M, Clurman BE. Fbw7 ubiquitin ligase: a tumour suppressor at the crossroads of cell division, growth and differentiation. Nat Rev Cancer. 2008; 8: 83-93.

6. Spruck CH, Strohmaier H, Sangfelt O, Müller HM, Hubalek M, Müller-Holzner E, Marth C, Widschwendter M, Reed SI. Hcdc4 gene mutations in endometrial cancer. Cancer Res. 2002; 62: 4535-4539.

7. Koepp DM, Schaefer LK, Ye X, Keyomarsi K, Chu C, Harper JW, Elledge SJ. Phosphorylation-dependent ubiquitination of cyclin e by the scffbw7 ubiquitin ligase. Science. 2001; 294: 173-177.

8. Nateri AS, Riera-Sans L, Da Costa C, Behrens A. The ubiquitin ligase scffbw7 antagonizes apoptotic jnk signaling. Science. 2004; 303: 1374-1378.
9. Wei W, Jin J, Schlisio S, Harper JW, Kaelin WG. The v-jun point mutation allows c-jun to escape gsk3-dependent recognition and destruction by the fbw 7 ubiquitin ligase. Cancer Cell. 2005; 8: 25-33.

10. Welcker M, Orian A, Jin J, Grim JE, Grim JA, Harper JW, Eisenman RN, Clurman BE. The fbw7 tumor suppressor regulates glycogen synthase kinase 3 phosphorylationdependent c-myc protein degradation. Proc Natl Acad Sci U S A. 2004; 101: 9085-9090.

11. Yada M, Hatakeyama S, Kamura T, Nishiyama M, Tsunematsu R, Imaki H, Ishida N, Okumura F, Nakayama K, Nakayama KI. Phosphorylation-dependent degradation of c-myc is mediated by the f-box protein fbw7. EMBO J. 2004; 23: 2116-2125.

12. Inuzuka H, Shaik S, Onoyama I, Gao D, Tseng A, Maser RS, Zhai B, Wan L, Gutierrez A, Lau AW, Xiao Y, Christie $\mathrm{AL}$, Aster J, et al. $\operatorname{Scf}(\mathrm{fbw} 7)$ regulates cellular apoptosis by targeting mcl1 for ubiquitylation and destruction. Nature. 2011; 471: 104-109.

13. Wertz IE, Kusam S, Lam C, Okamoto T, Sandoval W, Anderson DJ, Helgason E, Ernst JA, Eby M, Liu J, Belmont LD, Kaminker JS, O'Rourke KM, et al. Sensitivity to antitubulin chemotherapeutics is regulated by mcll and fbw7. Nature. 2011; 471: 110-114.

14. Snyder JL, Kearns CA, Appel B. Fbxw7 regulates notch to control specification of neural precursors for oligodendrocyte fate. Neural Dev. 2012; 7: 15.

15. Fryer CJ, White JB, Jones KA. Mastermind recruits cycc:Cdk8 to phosphorylate the notch icd and coordinate activation with turnover. Mol Cell. 2004; 16: 509-520.

16. Tetzlaff MT, Yu W, Li M, Zhang P, Finegold M, Mahon K, Harper JW, Schwartz RJ, Elledge SJ. Defective cardiovascular development and elevated cyclin e and notch proteins in mice lacking the fbw7 f-box protein. Proc Natl Acad Sci U S A. 2004; 101: 3338-3345.

17. Tsunematsu R, Nakayama $K$, Oike $Y$, Nishiyama $M$, Ishida N, Hatakeyama S, Bessho Y, Kageyama R, Suda T, Nakayama KI. Mouse fbw7/sel-10/cdc4 is required for notch degradation during vascular development. J Biol Chem. 2004; 279: 9417-9423.

18. Mao JH, Perez-Losada J, Wu D, Delrosario R, Tsunematsu R, Nakayama KI, Brown K, Bryson S, Balmain A. Fbxw7/cde4 is a p53-dependent, haploinsufficient tumour suppressor gene. Nature. 2004; 432: 775-779.

19. Kwon YW, Kim IJ, Wu D, Lu J, Stock WA, Liu Y, Huang Y, Kang HC, DelRosario R, Jen KY, Perez-Losada J, Wei $\mathrm{G}$, Balmain A, et al. Pten regulates aurora-a and cooperates with fbxw7 in modulating radiation-induced tumor development. Mol Cancer Res. 2012; 10: 834-844.

20. Wang R, Wang Y, Liu N, Ren C, Jiang C, Zhang K, Yu S, Chen Y, Tang H, Deng Q, Fu C, Li R, Liu M, et al. Fbw7 regulates endothelial functions by targeting klf2 for ubiquitination and degradation. Cell Res. 2013; 23: 803-819. 
21. Mao JH, Kim IJ, Wu D, Climent J, Kang HC, DelRosario R, Balmain A. Fbxw7 targets mtor for degradation and cooperates with pten in tumor suppression. Science. 2008; 321: 1499-1502.

22. Bengoechea-Alonso MT, Ericsson J. Tumor suppressor fbxw7 regulates $\operatorname{tgf} \beta$ signaling by targeting tgif1 for degradation. Oncogene. 2010; 29: 5322-5328.

23. Cao J, Ge MH, Ling ZQ. Fbxw7 tumor suppressor: a vital regulator contributes to human tumorigenesis. Medicine (Baltimore). 2016; 95: e2496.

24. Akhoondi S, Sun D, von der Lehr N, Apostolidou S, Klotz K, Maljukova A, Cepeda D, Fiegl H, Dafou D, Dofou D, Marth C, Mueller-Holzner E, Corcoran M, et al. Fbxw7/ hcde4 is a general tumor suppressor in human cancer. Cancer Res. 2007; 67: 9006-9012.

25. Malapelle U, Pisapia P, Sgariglia R, Vigliar E, Biglietto M, Carlomagno C, Giuffrè G, Bellevicine C, Troncone G. Less frequently mutated genes in colorectal cancer: evidences from next-generation sequencing of 653 routine cases. J Clin Pathol. 2016.

26. Kemp Z, Rowan A, Chambers W, Wortham N, Halford S, Sieber O, Mortensen N, von Herbay A, Gunther T, Ilyas M, Tomlinson I. Cdc4 mutations occur in a subset of colorectal cancers but are not predicted to cause loss of function and are not associated with chromosomal instability. Cancer Res. 2005; 65: 11361-11366.

27. Rajagopalan H, Jallepalli PV, Rago C, Velculescu VE, Kinzler KW, Vogelstein B, Lengauer C. Inactivation of hcdc4 can cause chromosomal instability. Nature. 2004; 428: 77-81.

28. Bai C, Sen P, Hofmann K, Ma L, Goebl M, Harper JW, Elledge SJ. Skp1 connects cell cycle regulators to the ubiquitin proteolysis machinery through a novel motif, the f-box. Cell. 1996; 86: 263-274.

29. Orlicky S, Tang X, Willems A, Tyers M, Sicheri F. Structural basis for phosphodependent substrate selection and orientation by the scfcdc4 ubiquitin ligase. Cell. 2003; 112: 243-256.

30. Hao B, Oehlmann S, Sowa ME, Harper JW, Pavletich NP. Structure of a fbw7-skp1-cyclin e complex: multisitephosphorylated substrate recognition by scf ubiquitin ligases. Mol Cell. 2007; 26: 131-143.

31. Welcker M, Clurman BE. Fbw $7 /$ hedc4 dimerization regulates its substrate interactions. Cell Div. 2007; 2: 7.

32. Jardim DL, Wheler JJ, Hess K, Tsimberidou AM, Zinner R, Janku F, Subbiah V, Naing A, Piha-Paul SA, Westin SN, Roy-Chowdhuri S, Meric-Bernstam F, Hong DS. Fbxw7 mutations in patients with advanced cancers: Clinical and molecular characteristics and outcomes with mtor inhibitors. PLoS One. 2014; 9: e89388.

33. Chang CC, Lin HH, Lin JK, Lin CC, Lan YT, Wang HS, Yang SH, Chen WS, Lin TC, Jiang JK, Chang SC. Fbxw7 mutation analysis and its correlation with clinicopathological features and prognosis in colorectal cancer patients. Int J Biol Markers. 2015; 30: e88-95.
34. Cancer Genome Atlas Network. Comprehensive molecular characterization of human colon and rectal cancer. Nature. 2012; 487: 330-337.

35. Davis H, Lewis A, Behrens A, Tomlinson I. Investigation of the atypical fbxw7 mutation spectrum in human tumours by conditional expression of a heterozygous propellor tip missense allele in the mouse intestines. Gut. 2014; 63: 792-799.

36. Mouradov D, Domingo E, Gibbs P, Jorissen RN, Li S, Soo PY, Lipton L, Desai J, Danielsen HE, Oukrif D, Novelli M, Yau C, Holmes CC, et al. Survival in stage ii/iii colorectal cancer is independently predicted by chromosomal and microsatellite instability, but not by specific driver mutations. Am J Gastroenterol. 2013; 108: 1785-1793.

37. Maughan TS, Adams RA, Smith CG, Meade AM, Seymour MT, Wilson RH, Idziaszczyk S, Harris R, Fisher D, Kenny SL, Kay E, Mitchell JK, Madi A, et al. Addition of cetuximab to oxaliplatin-based first-line combination chemotherapy for treatment of advanced colorectal cancer: results of the randomised phase $3 \mathrm{mrc}$ coin trial. Lancet. 2011; 377: 2103-2114.

38. Shen Y, Han X, Wang J, Wang S, Yang H, Lu SH, Shi Y. Prognostic impact of mutation profiling in patients with stage ii and iii colon cancer. Sci Rep. 2016; 6: 24310.

39. Forbes SA, Beare D, Gunasekaran P, Leung K, Bindal N, Boutselakis H, Ding M, Bamford S, Cole C, Ward S, Kok CY, Jia M, De T, et al. Cosmic: exploring the world's knowledge of somatic mutations in human cancer. Nucleic Acids Res. 2015; 43: D805-811.

40. Lupini L, Bassi C, Mlcochova J, Musa G, Russo M, Vychytilova-Faltejskova P, Svoboda M, Sabbioni S, Nemecek R, Slaby O, Negrini M. Prediction of response to anti-egfr antibody-based therapies by multigene sequencing in colorectal cancer patients. BMC Cancer. 2015; $15: 808$.

41. Aydin IT, Melamed RD, Adams SJ, Castillo-Martin M, Demir A, Bryk D, Brunner G, Cordon-Cardo C, Osman I, Rabadan R, Celebi JT. Fbxw7 mutations in melanoma and a new therapeutic paradigm. J Natl Cancer Inst. 2014; 106: dju107.

42. O’Neil J, Grim J, Strack P, Rao S, Tibbitts D, Winter C, Hardwick J, Welcker M, Meijerink JP, Pieters R, Draetta G, Sears R, Clurman BE, et al. Fbw7 mutations in leukemic cells mediate notch pathway activation and resistance to gammasecretase inhibitors. J Exp Med. 2007; 204: 1813-1824.

43. Sancho R, Jandke A, Davis H, Diefenbacher ME, Tomlinson I, Behrens A. F-box and wd repeat domain-containing 7 regulates intestinal cell lineage commitment and is a haploinsufficient tumor suppressor. Gastroenterology. 2010; 139: 929-941.

44. Edge SB, Compton CC. The American Joint Committee on Cancer: the 7th edition of the AJCC cancer staging manual and the future of TNM. Ann Surg Oncol. 2010; 17: 1471-1474. 